\title{
A comparison of mental health legislation in five developed countries: a narrative review
}

\author{
T. Cronin ${ }^{1, *}$, P. Gouda ${ }^{2}$, C. McDonald ${ }^{1,3}$ and B. Hallahan ${ }^{1,3}$ \\ ${ }^{1}$ Department of Psychiatry, University Hospital Galway, Galway Roscommon Mental Health Services, Galway, Ireland \\ ${ }^{2}$ Division of Internal Medicine, University of Calgary, Alberta, Canada \\ ${ }^{3}$ School of Medicine, Clinical Science Institute, National University of Ireland Galway, Galway, Ireland
}

Objectives. To describe similarities and differences in mental health legislation between five jurisdictions: the Republic of Ireland, England and Wales, Scotland, Ontario (Canada), and Victoria (Australia).

Methods. An in-depth examination was undertaken focussing on the process of involuntary admission, review of Admission Orders and the legal processes in relation to treatment in the absence of patient consent in each of the five jurisdictions of interest.

Results. All jurisdictions permit the detention of a patient if they have a mental disorder although the definition of mental disorder varies between jurisdictions. Several additional differences exist between the five jurisdictions, including the duration of admission prior to independent review of involuntary detention and the role of supported decision making.

Conclusions. Across the five jurisdictions examined, largely similar procedures for admission, detention and treatment of involuntary patients are employed, reflecting adherence with international standards and incorporation of human rights-based principles. Differences exist in relation to the criteria to define mental disorder, the occurrence of automatic review hearings in a timely fashion after a patient is involuntarily admitted and the role for supported decision making under mental health legislation.

Received 30 April 2017; Revised 19 July 2017; Accepted 27 July 2017

Key words: Consent to treatment, Mental Health Act 2001, mental health legislation, mental health tribunals.

\section{Introduction}

On 1 November 2006, the Mental Health Act (MHA) 2001 replaced the previous legislation, the Mental Treatment Act 1945, relating to the involuntary detention and treatment of patients in the Republic of Ireland. International legal frameworks including the European Convention for the Protection of Human Rights and Fundamental Freedoms (ECHR) (1950) and the United Nations (UN) Principles for the Protection of Persons with Mental Illness and Improvement of Mental Health Care (UN, 1991) were considered in the drafting of the MHA 2001. These frameworks have also shaped UK mental health law reform. Other jurisdictions have also utilised frameworks to shape their mental health laws. For example, in Canada, the Charter of Rights and Freedoms (The Constitution Act, 1982) guarantees certain rights to Canadian citizens, while in Victoria, Australia, the Charter of Human Rights and Responsibilities Act (2006) protects the rights of its citizens. Mental health law must adhere, as so far as is possible, to these charters.

* Address for correspondence: T. Cronin, Department of Psychiatry, University Hospital Galway, Newcastle Road, Galway H91 YR71, Ireland. (Email: tom.cronin3@hse.ie)
The World Health Organisation (WHO) as the directing and coordinating authority for health within UN systems have published 10 basic principles for mental health law based on comparative analysis of mental health legislation in 45 countries worldwide (WHO, 1996). These 10 principles emphasise that mental health care should be provided in the least restrictive fashion possible and in the case of a decision affecting bodily integrity (i.e. treatment) or liberty (i.e. hospitalisation) with a long-lasting impact, that there should be automatic periodic review (WHO, 1996). In the Republic of Ireland, the MHA 2001 introduced significant improvements in relation to the involuntary admission and treatment of patients. These included the removal of detention orders of indefinite duration (Person of Unsound Mind), the provision of automatic independent reviews of detention orders by mental health tribunals (MHTs), and provision of free legal representation and independent psychiatric opinions.

Despite such progress, rights-based legislation may not necessarily be concordant with reformed modern mental health laws. The UN (2006) Convention on the Rights of Persons with Disabilities (CRPD), a major treaty that underpins and protects the rights of those with disabilities, has been ratified by 164 countries. 
The convention is potentially at odds with modern mental health law as it specifically prohibits the detention and treatment without consent of anyone based on the criterion of 'disability' (mental illness would be considered a disability, according to the convention) (Kelly, 2014).

Despite many countries ratifying the UN CRPD, mental health law varies in practice depending on historical and cultural factors. Different practices exist around the process of involuntary admission, review of detention orders and the legal processes in relation to treatment in the absence of patient consent. In the current selective review, we aimed to evaluate and compare mental health legislation for adults in five jurisdictions within developed and culturally similar countries [Republic of Ireland, England and Wales, Ontario (Canada), Victoria (Australia), and Scotland] that have implemented recent amendments in line with human rights framework to their respective mental health legislative systems. From an Irish perspective, we are particularly interested in comparing mental health legislation in light of recommendations made by the Expert Group on the MHA 2001 (Department of Health, 2014). The focus of this review concentrates on the process of involuntary detention, review of detention orders and the legal processes in relation to treatment in the absence of patient consent. As Ireland does not currently have Community Treatment Orders (CTOs), these are not discussed in detail in this article, however, they are included as they are a form of compulsory treatment utilised in the other four jurisdictions.

\section{Methods}

An in-depth examination in relation to the operation of MHA legislation in five jurisdictions was undertaken and included mental health legislation in the Republic of Ireland (MHA, 2001), England and Wales (1983) (most recently amended in 2007), Ontario (1990), Scotland (2003), and Victoria (MHA, 2014). In Canada, each province has its own mental health legislation and although many are similar the Ontario MHA was chosen as it was most recently amended. In Australia commonwealth laws including the National Standards for Mental Health Services (Department of Health, 2010), apply to each province; however, some aspects of mental health legislation are governed by each of the eight separate jurisdictions. In this article, we focussed on Victoria's MHA, as it was most recently enacted in 2014.

Each MHA was reviewed in detail (see reference section access details). The principal aspects of each MHA legislation examined included: (1) the process of involuntary admission, (2) the review process for individuals admitted under their respective mental health legislation and (3) mental health legislation regulations in relation to treatment without consent. In addition, a literature search was conducted of electronic databases, including PubMed, Google Scholar and Scopus. We searched for articles between 2000 and 2017 using Medical Subject Headings key terms: Mental Health Act OR mental health legislation OR mental health law. Similarities or differences between legislation were compared against the background of international human rights standards.

\section{Results}

\section{Involuntary admission}

\section{Criteria}

The criteria to initiate an involuntary detention are set out in Table 1. In all jurisdictions, a patient may be detained if they have a mental disorder (or illness) that significantly impairs judgement. The definition of mental disorder varies across jurisdictions. The MHA in Ontario describes a mental disorder simply as 'any disease or disability of the mind'; whereas in Scotland and Victoria a list of exclusion criteria are included. For example, in Victoria, a person is not considered to have a mental illness for several reasons including that the person expresses or refuses or fails to express a particular political, religious, or philosophical opinion or belief. In England and Wales, Scotland, and Victoria, personality disorder is specifically included in the definition of a mental disorder, while it is explicitly excluded in the Republic of Ireland. Each jurisdiction excludes psycho-active substance misuse or dependence as mental disorders. In addition to having a mental disorder, the presence of significant risk to self or others qualifies individuals for detention under the various mental health legislations; however, individuals may also potentially be detained without such risk being present. Risk to self or others is separate to deterioration in mental state in the MHAs of Victoria and the Republic of Ireland.

Mental health legislation provides civil compulsory powers to bring a patient to an approved centre and be detained there although variation between jurisdictions exists. For example, England and Wales, Scotland, and Victoria have separate assessment and treatment orders representing different sections of mental health legislation that may be used, while in Ontario and the Republic of Ireland only one order is utilised to admit and detain a patient. While a 'need for treatment' is an option, it is not mandatory for a patients' involuntary admission in Ontario and the Republic of Ireland. In Victoria, a need for treatment is a condition of an Assessment Order, but treatment may not be given without consent unless urgently required. 
Table 1. Mental Health Act legislation: comparison between jurisdictions regarding admission and detention

\begin{tabular}{|c|c|c|c|c|c|}
\hline & Republic of Ireland & England and Wales & Victoria & Ontario & Scotland \\
\hline Diagnosis of a mental disorder required & Yes & Yes & Yes & Yes & Yes \\
\hline Personality disorder included as a mental disorder & No & Yes & Yes & Yes & Yes \\
\hline $\begin{array}{l}\text { Alcohol or psycho-active substance } \\
\text { dependence included as a mental disorder }\end{array}$ & No & No & No & No & No \\
\hline Risk to self or others required & Yes & Yes & Yes & Yes & Yes \\
\hline A lack of capacity explicitly required & $\begin{array}{l}\text { No } \\
\text { 'Impaired judgement' }\end{array}$ & No & $\begin{array}{l}\text { No } \\
\text { 'Impaired judgement' }\end{array}$ & Yes & $\begin{array}{l}\text { No } \\
\text { 'Impaired judgement' }\end{array}$ \\
\hline Patient requires treatment & $\begin{array}{l}\text { Not mandatory for all } \\
\text { patients }\end{array}$ & Yes & Yes & $\begin{array}{l}\text { Not mandatory for all } \\
\text { patients }\end{array}$ & Yes \\
\hline Assessment Orders utilised & No & Yes & Yes & No & Yes \\
\hline $\begin{array}{l}\text { Possible applicants for a patients' involuntary } \\
\text { detention }\end{array}$ & $\begin{array}{l}\text { Relative } \\
\text { Authorised officer } \\
\text { Member of police } \\
\text { Any other person }\end{array}$ & $\begin{array}{l}\text { Nearest relative } \\
\text { AMHP }\end{array}$ & Not required & Not required & Medical practitioner \\
\hline Recommendation & $\begin{array}{l}1 \text { Registered medical } \\
\text { practitioner }\end{array}$ & 2 Registered medical practitioners & $\begin{array}{l}\text { A MHP and medical } \\
\text { practitioner }\end{array}$ & 1 Medical practitioner & $\mathrm{MHO}$ \\
\hline Recommendation period $^{\mathrm{a}}$ & 7 days & 28 days & 72 hours & 7 days & 28 days \\
\hline Deciding authority for order & Medical & Medical & Medical & Medical & Medical \\
\hline Signing of $\mathrm{AO}$ & Consultant psychiatrist & Approved clinician & MHT & Physician & MHT \\
\hline Types of AO & $\mathrm{AO}$ & $\begin{array}{l}\text { Emergency detention order } \\
\text { Admission for assessment } \\
\text { admission for treatment }\end{array}$ & $\begin{array}{l}\text { Assessment Order } \\
\text { Treatment Order }\end{array}$ & $\begin{array}{l}\text { Certificate of involuntary } \\
\text { admission }\end{array}$ & $\begin{array}{l}\text { Emergency Order } \\
\text { Short-term detention order } \\
\text { Compulsory Treatment Order }\end{array}$ \\
\hline Mandatory inclusion of patient counsel & Yes & Yes & Yes & Yes & Yes \\
\hline $\begin{array}{l}\text { Assessment period in hospital prior to } \\
\text { completion of AO by consultant psychiatrist }\end{array}$ & 24 hours & 28 days & $\begin{array}{l}24 \text { hours with extension } \\
\text { of up to } 48 \text { hours }\end{array}$ & 72 hours & 72 hours \\
\hline Durations of Renewal Orders & $\begin{array}{l}3 \text { weeks } \\
3 \text { months } \\
6 \text { months } \\
12 \text { monthly }\end{array}$ & $\begin{array}{l}4 \text { weeks } \\
3 \text { months } \\
6 \text { months } \\
12 \text { monthly } \\
\text { Or if a CTO } \\
6 \text { monthly } \\
12 \text { monthly }\end{array}$ & 6 monthly & $\begin{array}{l}2 \text { weeks } \\
4 \text { weeks } \\
2 \text { months } \\
3 \text { monthly }\end{array}$ & $\begin{array}{l}28 \text { days } \\
6 \text { months } \\
12 \text { monthly }\end{array}$ \\
\hline MHT & Automatic & Patient request & Patient request & Automatic & Automatic \\
\hline Detention time before tribunal (maximum) & 21 days & 14 days & 7 days & 28 days & 28 \\
\hline Tribunal board members & $\begin{array}{l}\text { Psychiatrist, solicitor or } \\
\text { barrister, lay person }\end{array}$ & $\begin{array}{l}\text { Psychiatrist, solicitor or barrister, } \\
\text { medical professional }\end{array}$ & $\begin{array}{l}\text { Psychiatrist, solicitor or } \\
\text { barrister, lay person }\end{array}$ & $\begin{array}{l}\text { Psychiatrist or medical } \\
\text { doctor, solicitor or } \\
\text { barrister, lay person }\end{array}$ & $\begin{array}{l}\text { Psychiatrist or medical doctor, } \\
\text { solicitor or barrister, lay } \\
\text { person }\end{array}$ \\
\hline Appeal detention order & Yes & Yes & Yes & Yes & Yes \\
\hline Appeal process & Yes: Circuit Court & Yes: Upper Tribunal & $\begin{array}{l}\text { Yes: Superior Court of } \\
\text { Justice }\end{array}$ & $\begin{array}{l}\text { Board Appeal: Appeal to } \\
\text { Victorian Civil and } \\
\text { Administrative } \\
\text { Tribunal, Supreme } \\
\text { Court }\end{array}$ & $\begin{array}{l}\text { Sheriff Principal: } \\
\text { Court of Session }\end{array}$ \\
\hline
\end{tabular}

APMH, Approved mental health professional; MHP, mental health practitioner; MHO, mental health officer; AO, Admission Order; MHT, mental health tribunal; CTO, Community Treatment Order.

${ }^{a}$ Recommendation period is the maximum duration of time that a recommendation can stay in place prior to a patient being brought to an acute psychiatric inpatient unit. When this time has elapsed, if the patient has not arrived in an acute psychiatric inpatient unit, the process is null and void. 
Impaired decision making is a criterion for involuntary admission under mental health legislation in Scotland and Victoria, but only Ontario explicitly states that a patient must lack capacity.

\section{Application process}

Practices relating to applications for patients to be admitted involuntarily under respective mental health legislations differ between jurisdictions. In the Republic of Ireland, four separate forms, depending on who is making the application, are utilised (see Table 1). In Scotland, only a mental health officer (MHO), generally a social worker or medical practitioner, can make an application, whilst in Ontario only a medical practitioner can make an application for a patients' detention under their mental health legislation (see Table 1).

\section{Detention orders}

In contrast to Ontario and the Republic of Ireland; England and Wales, Scotland, and Victoria have separate detention orders, utilising different parts of their mental health legislation, that affect criteria for the detention of a patient, the duration of detention and treatment. These are: brief 'emergency' detention orders, short-term detention orders often used for the purposes of assessment and long-term compulsory Treatment Orders (see Table 1). For example, emergency detention orders used in England and Wales, and Scotland require only one medical practitioner to make an application and the maximum period of detention is relatively brief (72 hours). In Scotland, an approved medical practitioner, that is consultant psychiatrist, must seek the 'consent' or recommendation of a MHO before granting a 'short-term detention certificate'. In Victoria, a patient may be detained under an 'Assessment Order' for up to 72 hours with this period extendable by a consultant psychiatrist by a maximum of 48 hours, after which the consultant psychiatrist may sign a Temporary Treatment Order. After the patient's first MHT, this may result in the patient being subject to a Treatment Order. For a patient is to be compulsory admitted under Treatment Orders in England and Wales, and Scotland, two doctors, including the patient's treating consultant psychiatrist, make an application for compulsory treatment. They provide separate reports to a $\mathrm{MHO}$ who assesses the patient and then submits an application to the MHT to bring the patient to an acute psychiatric inpatient unit for treatment, with the MHT completing the compulsory Treatment Order.

\section{Capacity}

Ontario is the only jurisdiction where 'a lack of capa-

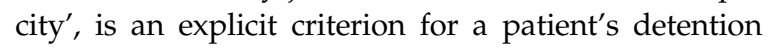

under the mental health legislation, although the related concept of 'impaired judgement' is a criterion under the legislation in the Republic of Ireland, Scotland and Victoria.

In all jurisdictions, it is mandatory to inform the patient of their detention and provide information relating to their involuntary status and right of appeal of same.

\section{Review of detention}

MHT

The process of review of a patients' involuntary admission under the relevant mental health legislation differs between the five jurisdictions. A MHT is only automatic in the Republic of Ireland, Scotland and Ontario; with the time to tribunal hearing ranging from 7 days in Victoria to 28 days in Ontario and Scotland (see Table 1). However, in England and Wales, and Scotland, those patients previously known to the mental health services who are directly admitted to the acute psychiatric inpatient unit under a Treatment Order can be detained for up to 6 months prior to an automatic MHT hearing, although patients can request an earlier MHT (Table 1). MHT board members consist of three individuals in each jurisdiction, however, in England and Wales a medical professional is the third board member in addition to a psychiatrist and solicitor or barrister unlike the other jurisdictions where this individual is a 'lay person'. A MHT can occur after the Admission Order (AO)or Renewal Order in each jurisdiction with the time periods for subsequent orders being longer in duration up to a maximum of 12 months, except in Ontario (3 months) and Victoria (6 months). However, in England and Wales it can conceivably be up to 3 years before an automatic MHT if a patient is on a long-term compulsory Treatment Order.

\section{Appeal of an $A O$}

Patients have the legal right to appeal their AO once per order, in each jurisdiction. Renewal Orders can be repeated indefinitely but each one must be reviewed by an independent MHT board in all jurisdictions. As part of a patient's independent review, prior to the MHT hearing, a second opinion is provided by a consultant psychiatrist. This is usually the consultant psychiatrist that sits on the MHT panel. However, in Ireland the second opinion is provided by an independent consultant psychiatrist who submits a report to the MHT board. The function of a MHT varies between jurisdictions, with the MHT board making the AO in Victoria and Scotland, unlike in the other jurisdictions where the AO or Renewal Order is signed by the 
consultant psychiatrist treating the patient, with the MHT affirming or revoking this order.

\section{Treatment}

MHA legislation regulations in relation to treatment in the five jurisdictions are described and compared in Table 2. In Ontario, unlike the other four jurisdictions, decisions in relation to treatment with medications against consent are made under the Health Care Consent Act (HCCA) (1996) rather than their MHA (1990).

\section{Restricted treatments}

Certain treatments are explicitly restricted under mental health legislation including medications prescribed over a continuous period, electroconvulsive therapy (ECT) and psychosurgery. In England and Wales, Scotland, and the Republic of Ireland, treatment with medications without consent requires the authorisation of an independent consultant psychiatrist, with this required within 2-3 months of a patients involuntary admission and at similar intervals after this, if the patient remains detained under the legislation. The administration of ECT to a patient detained under mental health legislation requires authorisation either by an independent second opinion psychiatrist (England and Wales, Scotland, the Republic of Ireland) or by a MHT in Ontario and Victoria. No jurisdiction permits psychosurgery where a patient refuses this procedure, even if they are considered to lack capacity, and psychosurgery cannot be administered to an involuntary patient in Victoria. For voluntary patients, MHT approval or authorisation by an independent second opinion consultant psychiatrist is required for a patient to undergo psychosurgery in each jurisdiction, with two lay persons appointed by the Mental Welfare Commission also required to authorise psychosurgery in Scotland (see Table 2).

\section{Restrictive measures}

A variety of restrictive measures, including the use of seclusion, rapid tranquilisation and restraint are permitted under mental health legislation. The use of such interventions are guided by codes of practice, policies and other forms of governance at national and/or local level to varying degrees of detail. Although such interventions should be provided in the least restrictive way, as stated in codes of practice, only Victoria and Scotland explicitly state the term 'least restrictive' as a guiding principle in their legislation. Seclusion use must be reviewed at least every 4 hours in the Republic of Ireland and Victoria by a mental health professional.

\section{Nominated persons}

With the exception of the Republic of Ireland, patients may have a 'nominated person' that can assist them regarding treatment choice. In Scotland, for example, the 'named person' may apply to the MHT for a review of the treatment order while in Victoria the named person must be informed if restrictive practices have been used. A provision for advanced statements by patients that set out preferences regarding treatment is also present in Ontario, Scotland and Victoria; however, it is not compulsory for the treating consultant psychiatrists to adhere to these statements but must take them into consideration when deciding on treatment modalities. In Scotland and Victoria, treatment choices that conflict with the advanced statement must be documented and a reason provided. In Ontario, under the HCCA legislation, a substitute decision maker is appointed (usually a family member), who may provide consent or refuse treatment.

\section{Discussion}

International human rights frameworks including the CRPD and ECHR have influenced much of modern mental health legislation reform and consequently, it is not surprising that largely similar procedures and safeguards for admission, detention and treatment of involuntary patients are utilised in these jurisdictions, reflecting adherence with international standards (Kelly, 2011). Indeed, ratification of such treaties by countries has led to amendments of existing mental health legislation due to non-adherence with these human rights frameworks (MHA, 2007). However, several differences also exist between the different jurisdictions. These include the diagnostic criteria required for involuntary detention; the duration to independent review of both involuntary detention and treatment administered and role of supported decision making.

The criteria for detention under the various MHA legislations are similar but not identical between the jurisdictions examined. The inclusion of personality disorder as a mental disorder is not included in the MHA 2001, unlike mental health legislation in other jurisdictions. The reasons to exclude or include personality disorders are complex and concern a lack of clinical consensus in areas such as impaired decision making, risk and appropriate treatment. Whilst each jurisdiction has some exclusion criteria in relation to what categorises a mental illness (e.g. psycho-active substance misuse), the longer list of exclusion criteria in the MHA legislations of Scotland and Victoria is more in keeping with a human rights code, defining mental illness (that could result in involuntary admission) and the grounds for involuntary detention as narrowly as possible (Gray et al. 2010). This should potentially be considered in future mental health legislation in the Republic of Ireland. The recent report of the Expert Group on the review of the MHA 2001, recommended 
Table 2. Treatment under mental health legislation

\begin{tabular}{|c|c|c|c|c|c|}
\hline & Republic of Ireland & England and Wales & Victoria & Ontario & Scotland \\
\hline $\begin{array}{l}\text { Treatment without consent } \\
\text { during assessment period } \\
\text { prior to completion of } \mathrm{AO}^{\mathrm{a}}\end{array}$ & $\begin{array}{l}\text { Yes (under common } \\
\text { law) }\end{array}$ & Yes & Emergency only & Emergency only & Yes \\
\hline $\begin{array}{l}\text { Treatment without consent as } \\
\text { under MHA }\end{array}$ & Yes & Yes & Yes & Yes & Yes \\
\hline $\begin{array}{l}\text { Legislation applying to } \\
\text { treatment without consent }\end{array}$ & MHA & MHA & MHA & HCCA & MHA \\
\hline $\begin{array}{l}\text { Duration of treatment without } \\
\text { consent prior to independent } \\
\text { review }\end{array}$ & $\begin{array}{l}\text { Every } 3 \text { months } \\
\text { Second opinion } \\
\text { approval }\end{array}$ & $\begin{array}{l}3 \text { monthly } \\
\text { Second opinion approval }\end{array}$ & No timeframe specified & No timeframe specified & $\begin{array}{l}2 \text { monthly } \\
\text { Second opinion }\end{array}$ \\
\hline CTOs & No & Yes & Yes & Yes & Yes \\
\hline $\begin{array}{l}\text { Appeal of treatment without } \\
\text { consent }\end{array}$ & Yes & Yes & Yes & Yes & Yes \\
\hline ECT & $\begin{array}{l}\text { Yes: patient lacks } \\
\text { capacity. Second } \\
\text { opinion approval }\end{array}$ & $\begin{array}{l}\text { Yes: patient lacks capacity. Second } \\
\text { opinion approval. } \\
\text { No valid advance decision by } \\
\text { patient refusing ECT under MHC } \\
2005 \text { Act }\end{array}$ & $\begin{array}{l}\text { Yes: patient lacks capacity. } \\
\text { MHT approval }\end{array}$ & $\begin{array}{l}\text { Yes: patient lacks capacity. } \\
\text { MHT approval }\end{array}$ & $\begin{array}{l}\text { Yes: patient lacks capacity. } \\
\text { Second opinion approval }\end{array}$ \\
\hline $\begin{array}{l}\text { Psychosurgery - involuntary } \\
\text { patient }\end{array}$ & $\begin{array}{l}\text { Yes: patient consent } \\
\text { and MHT approval }\end{array}$ & $\begin{array}{l}\text { Yes: patient consent, second opinion } \\
\text { approval and certified to have } \\
\text { capacity }\end{array}$ & No & $\begin{array}{l}\text { Yes: patient consent, MHT } \\
\text { approval and certified to } \\
\text { have capacity }\end{array}$ & $\begin{array}{l}\text { Yes: patient consent and patient } \\
\text { certified to have capacity, two } \\
\text { lay persons authorise }\end{array}$ \\
\hline $\begin{array}{l}\text { Psychosurgery - voluntary } \\
\text { patient }\end{array}$ & $\begin{array}{l}\text { Yes: patient consent } \\
\text { and MHT approval }\end{array}$ & $\begin{array}{l}\text { Yes: patient consent, second opinion } \\
\text { approval and patient certified to } \\
\text { have capacity }\end{array}$ & $\begin{array}{l}\text { Yes: patient consent, } \\
\text { MHT approval }\end{array}$ & $\begin{array}{l}\text { Yes: patient consent, MHT } \\
\text { approval and patient } \\
\text { certified to have capacity }\end{array}$ & $\begin{array}{l}\text { Yes: patient consents and second } \\
\text { opinion approval if patient } \\
\text { does not have capacity, two lay } \\
\text { persons authorise }\end{array}$ \\
\hline $\begin{array}{l}\text { Seclusion regulations and review } \\
\text { times for seclusion }\end{array}$ & Yes: 4 hourly review & Yes & Yes: 4 hourly review & Yes & Yes \\
\hline Mechanical restraint regulations & Yes & Yes & Yes & Yes & Yes \\
\hline Substitute decision-maker role & No & Yes & Yes & Yes & Yes \\
\hline Advanced statements & No & Yes & Yes & Yes & Yes \\
\hline
\end{tabular}

AO, Admission Order; MHA, Mental Health Act; HCCA, Health Care Consent Act; CTOs, Community Treatment Orders; ECT, electroconvulsive therapy; MHC, Mental Health Commission; MHT, mental health tribunal.

${ }^{a} \mathrm{An} \mathrm{AO}$ may not be completed by the treating consultant psychiatrist after patient review. 
revision of the criteria of mental disorder including the removal of the terms severe intellectual disability and severe dementia and recommended that mental disorder should no longer be defined in mental health legislation but instead a revised MHA should include a definition of mental illness and that this definition should be separated from the criteria for detention. The recommended definition of mental illness was that 'mental illness means a complex and changeable condition where the state of mind of a person affects the persons thinking, perceiving, emotion or judgement, and seriously impairs the mental function of the person to the extent that he or she requires treatment'.

In Scotland and Victoria, the MHT has a greater role compared with the other jurisdictions, for example, in relation to the making of Treatment Orders. In Scotland, a patient care plan must be submitted to the MHT as part of the requirements before ordering a CTO. The expert group report on the review of the MHA 2001 similarly proposed that the MHT has the authority to establish if the detained patient has an individual care plan.

The length of time a patient can be detained under their respective mental health legislations prior to a MHT hearing varies considerably between the jurisdictions and hearings are not necessarily automatic in England and Wales, and Victoria. Although, a formal and automatic review at regular intervals of involuntary admission is compatible with human rights standards as outlined by the ECHR, the experience of both patients and mental health professionals of MHTs is variable. Positive elements of MHTs include patient reports of being treated with dignity, attaining constructive communications after MHT decisions and of patients being more accepting of their involuntary admission after MHT (Disfeld \& McKenna, 2006; O'Donoghue et al. 2010; Thom \& Nakarada-Kordic, 2014). However, several negative aspects of MHTs have also being described including the anxiety and distress experienced by patients attending MHTs (Carney \& Tait, 2011; Thom \& Nakarada-Kordic, 2014), and the often adversarial nature of MHTs, which can impact on the relationship between patients and consultant psychiatrist, further increasing patient distress (Jabbar et al. 2010; Smyth et al. 2016). Thus, deciding on a timeframe prior to an automatic review of patients' formal detention is not straight forward. The recent report of the Expert Group in relation to the review of the MHA 2001 suggested that the current 21-day period (maximum) prior to MHT should be reduced to 14 days to be in greater concordance with Article 5(4) of the ECHR and states that reviews should take place 'speedily' (Department of Health, 2014). In this regard, patients detained in England and Wales, and Scotland for a period of up to 6 months prior to automatic review following appears excessive.
Additionally, MHT boards have differing levels of influence in relation to treatment, with some jurisdictions (Ontario and Victoria) requiring MHT approval for the administration of certain treatments such as ECT. The report of the Expert Group in relation to review of the MHA 2001 suggested that although the MHT board should not have the powers to make judgements in relation to treatment, MHTs should ensure that treatment is administered in accordance with appropriate policies and guidelines (Department of Health, 2014).

While the presence of mental illness and perceived danger may result in the deprivation of liberty, it does not necessarily mean there is the loss of the right to bodily integrity or autonomy 'except in emergency'. Further criteria, as set out in MHA legislation, must be fulfilled - assessment by the treating psychiatrist that is time limited - before involuntary treatment may occur. This is seen, for example, with the use of a Section 4 ('Emergency Order') in England and Wales where the reduced threshold for detention is balanced with a shorter period of detention and limitations on treatment given without consent.

A significant difference exists between the Ontario 'rights focus' and 'treatment focus' of other jurisdictions with capacity rather than mental health legislation utilised in this jurisdiction in relation to treatment without consent. A focus on capacity is potentially beneficial as it removes the dual focus of mental disorder and risk as grounds for detention and instead focusses on the capacity to determine treatment. It also demonstrates consistent ethical principles between branches of medical law by not discriminating between physical and mental illness. However, refusal of treatment may also prolong the duration of involuntary admission and potentially result in patients experiencing more restrictive practices such as seclusion and restraint (Gray et al. 2010). Under the HCCA, a patient cannot have treatment administered while they appeal the decision. This has led to cases where patients have been detained for up to 20 years because they cannot be treated without consent (Solomon et al. 2009).

The MHA 2001 does not include provisions for supported decision making such as advance statements and nominated persons whose opinions must be taken into account by the treating consultant psychiatrist and has been described as 'a shortcoming' of the MHA 2001 (Ramsay et al. 2013). Potential changes to the MHA 2001 to include 'advanced healthcare directives (AHDs)' as a means to achieve patient autonomy have been recommended by the Expert Group for the review of the MHA 2001. Such features are a common component of capacity legislation and are addressed in Ireland by the recently enacted capacity legislation, the Assisted Decision-Making (Capacity) Act 2015, which includes a provision for advanced directives, where a written 
document can provide guidance in relation to preferences regarding health care decisions at a time of future incompetence. Such AHDs will be not legally binding in certain instances including the treatment of mental illness in individuals detained under the MHA 2001. However, AHDs in most other circumstances (except when life-saving treatment in declined without an explicit reason why such treatment is being declined) will be legally binding including the treatment of physical illness in individuals detained under the MHA 2001 and treatment of mental disorder when individuals are not detained under the MHA 2001.

The incorporation of a human rights-based model of mental illness is not without its challenges. For example, the CRPD states that 'the existence of a disability shall in no case justify a deprivation of liberty' (Art. 14 (1)(b)). In this regard, current mental health legislation could potentially be deemed discriminatory as mental illness is considered a disability under the CRPD (Szmukler et al. 2014). Current mental health legislation relies largely on a criterion (disability) and risk, to detain a patient without any requirement to consider a patient's functional ability to make a decision and as a result, is potentially incompatible with the CRPD (Davidson et al. 2016). Amongst the legislative processes examined in this review, the HCCA currently employed in Ontario appears to best address this dilemma; however, negative consequences including extended periods of involuntary detention may occur. Having one legislation encompassing both mental health and capacity may also potentially address this issue (Szmukler et al. 2010; Szmukler \& Kelly, 2016); however, such legislation may have the paradoxical effect of depriving patients of other fundamental rights such as access to the highest standard of care if a patient refuses treatment and may thus also potentially be viewed as impinging on an individuals' human rights and increase risk both to the patient and to others (Freeman et al. 2015).

There are a number of limitations with this review. Only five jurisdictions were examined and thus other jurisdictions with differences in relation to the processes of involuntary detention, review of AOs and the legal processes in relation to treatment in the absence of patient consent were not examined. Additionally, we did not examine in this review all aspects of the mental health legislation in detail including the process of appeal of MHTs or CTOs, for example.

\section{Conclusion}

Across the five jurisdictions examined, largely similar procedures for admission, detention and treatment of involuntary patients were utilised in these jurisdictions, reflecting adherence with international standards and incorporation of human rights-based principles. However, several differences also exist between the different jurisdictions, including diagnostic criteria required for detention under the various MHA legislation, the duration to independent review of involuntary detention and role of supported decision making. The review highlights how culturally similar jurisdictions which have recently updated their mental health legislation have dealt with balancing the demands of providing care with respecting patient autonomy and adhering to human rights standards in relation to patients with severe mental illness detained in acute psychiatric inpatient units.

\section{Conflicts of Interest}

None.

\section{Ethical Standards}

The authors assert that all procedures contributing to this work comply with the ethical standards of the relevant national and institutional committee on human experimentation with the Helsinki Declaration of 1975, as revised in 2008. The authors assert that ethical approval was attained for publication of this article from the Clinical Research Ethics Committee for Galway University Hospitals and the National University of Ireland, Galway.

\section{Financial Support}

This research was supported by a Research Programme Grant in Mental Health Services Research from the Mental Health Commission (2010-2017).

\section{References}

Carney T, Tait D (2011). Mental health tribunals - rights, protection, or treatment? Lessons from the ARC linkage grant study? Psychiatry, Psychology and Law 18, 137-159.

Charter of Human Rights and Responsibilities Act (2006). Act No 43/2006. ( http:/ / www.legislation.vic.gov.au/ Domino/Web_Notes/LDMS/PubStatbook.nsf/ f932b66241ecf1b7ca256e92000e23be/54D73763EF9 DCA36CA2571B6002428B0/\$FILE/06-043a.pdf ). Accessed 6 March 2017.

Davidson G, Brophy L, Campbell J, Susan FJ, Gooding P, O'Brien AM (2016). An international comparison of legal frameworks for supported substitute decision-making in mental health services. International Journal of Law and Psychiatry 44, 30-40.

Department of Health (2010). National standards for mental health services. Department of Health: Australia.

Department of Health (2014). Report of the expert group on the review of the Mental Health Act 2001. (http:/ / www. mhcirl.ie/File/rpt_expgroupreview_mha2001.pdf). Accessed 7 December 2016. 
Disfeld K, McKenna B (2006). The therapeutic intent of the New Zealand mental health review tribunal. Psychiatry, Psychology and Law 13, 100-109.

European Convention for the Protection of Human Rights and Fundamental Freedoms (ECHR) (1950). Convention for the Protection of Human Rights and Fundamental Freedoms. Council of Europe: Rome.

Freeman MC, Kolappa K, de Almeida JMC, Kleinman A, Makhashvlli N, Phakathi S, Saraceno B, Thornicroft G (2015). Reversing hard won victories in the name of human rights: a critique of the General Comment on Article 12 of the UN Convention on the Rights of Persons with Disabilities. Lancet Psychiatry 2, 844-850.

Gray JE, McSherry BM, O'Reilly RL, Weller PJ (2010). Australian and Canadian Mental Health Acts compared. Australian and New Zealand Journal of Psychiatry 44, 1126-1131.

Health Care Consent Act (HCCA) (1996). Ontario. (https:/ / www.ontario.ca/laws/statute/96h02). 9 Accessed December 2016).

Jabbar F, Kelly BD, Casey P (2010). National survey of psychiatrists' responses to implementation of the Mental Health Act 2001 in Ireland. Irish Journal of Medical Science 179, 291-294.

Kelly BD (2011). Mental health legislation and human rights in England, Wales and the Republic of Ireland. International Journal of Law and Psychiatry 34, 439-454.

Kelly BD (2014). An end to psychiatric detention? Implications of the United Nations Convention on the Rights of Persons with Disabilities. British Journal of Psychiatry 204, 174-175.

Mental Health Act (MHA) (1990). Ontario. (https://www. ontario.ca/laws/statute/90m07). Accessed 9 December 2016.

Mental Health Act (MHA) (2001). Republic of Ireland. (http://www.irishstatutebook.ie/eli/2001/act/25/ enacted/en/html). Accessed 7 December 2016.

Mental Health Act (MHA) (2007). England and Wales. (http://www.legislation.gov.uk/ukpga/2007/12/ contents). Accessed 9 December 2016.

Mental Health Act (MHA) (2014). Victoria. (http:/ / www. legislation.vic.gov.au/Domino/Web_Notes/LDMS/ PubStatbook.nsf/51dea49770555ea6ca256da4001b90cd/ 0001F48EE2422A10CA257CB4001D32FB/\$FILE/14-026aa \%20authorised.pdf). Accessed 8 December 2016.
O'Donoghue B, Lyne J, Hill M, Larkin C, Feeney L, O'Callaghan E (2010). Involuntary admission from the patients' perspective. Social Psychiatry and Psychiatric Epidemiology 45, 631-638.

Ramsay H, Roche E, O'Donoghue B (2013). Five years after implementation: a review of the Irish Mental Health Act 2001. International Journal of Law and Psychiatry 36, 83-91.

Smyth S, Casey D, Cooney A, Higgins A, McGuinness D, Bainbridge E, Keys M, Georgieva I, Brosnan L, Beecher C, Hallahan B, McDonald C, Murphy K (2016). A qualitative exploration of stakeholders' perspectives of involuntary admission under the Mental Health Act 2001 in the Republic of Ireland. International Journal of Mental Health Nursing (in press).

Solomon R, O’Reilly R, Nikolic M, Gray J (2009). Treatment delayed liberty denied. Canadian Bar Review 87, 679-719.

Szmukler G, Daw R, Callard F (2014). Mental Health Law and the UN Convention on the Rights of Persons with Disabilities. International Journal of Law and Psychiatry 37, 245-252.

Szmukler G, Daw R, Dawson J (2010). A model law fusing incapacity and mental health legislation. International Journal of Mental Health Law 11, 11-24.

Szmukler G, Kelly BD (2016). We should replace conventional mental health law with capacity-based law. British Journal of Psychiatry 209, 449-453.

The Constitution Act (1982). Schedule B to the Canada Act 1982 (UK). (https:/ / www.canlii.org/en/ca/laws/stat/ schedule-b-to-the-canada-act-1982-uk-1982-c-11/latest/ schedule-b-to-the-canada-act-1982-uk-1982-c-11.htm). Accessed 6 March 2017.

Thom K, Nakarada-Kordic I (2014). Mental health review tribunals in action: a systematic review of the empirical literature. Psychiatry, Psychology and Law 21, 112-126.

United Nations (UN) (1991). Principles for the Protection of Persons with Mental Illness and the Improvement of Mental Health Care. United Nations: New York, NY.

United Nations (UN) (2006). Convention on the Rights of Persons with Disabilities. United Nations: New York, NY.

World Health Organisation (WHO) (1996). Mental Health Care Law: Ten Basic Principles. WHO: Geneva. 